\title{
Effect of fermentation on the acetate-dominated rumen microbial fuel cells
}

\author{
Chin Tsan Wang ${ }^{\mathrm{a}^{*}}$, Yao Cheng Lee ${ }^{\mathrm{b}}$, Che Ming Yang ${ }^{\mathrm{c}}$, Zih Sheng Chen ${ }^{\mathrm{a}}$, Yung \\ Chin Yang
}

\footnotetext{
${ }^{a}$ Department of Mechanical and Electro-Mechanical Engineering, National I-Lan University, I-Lan. Taiwan.

${ }^{b}$ Institute of Materials Science and Engineering, National Taipei University of Technology, Taipei. Taiwan

${ }^{c}$ Department of Biotechnology and Animal Science, National I-Lan University, I-Lan. Taiwan.
}

\begin{abstract}
Converting renewable biomass into electricity by using Microbial Fuel Cells (MFCs) can produce clean and transportable energy. Ruminal microorganisms are capable of degrading plant fiber with the production of Volatile Fatty Acids (VFA) and reducing equivalents which could then be transformed into electricity. In this study fermentation characteristics and electrical properties in microbial fuel cells with rumen microorganisms, using plant fiber as substrate, are investigated. Results show that an acetate-type of fermentation favors the yield of reducing equivalents. When bermudagrass straw and rumen microorganisms were added to the anode chamber of microbial fuel cells, the total VFA concentration increased with time. It seems that the accumulation of VFA interfered with the generation of electricity. These results imply that an acetate-dominated type of ruminal fermentation could lead to the release of electrons. This could be conducive to electrical output by Rumen Microbial Fuel Cells (RMFCs). These findings would be useful to improve the power generation of RMFCs.
\end{abstract}

Keywords: Volatile Fatty Acids (VFA), fermentation characteristics, rumen microorganisms, plant fiber, power performance, Rumen Microbial Fuel Cells (RMFCs)

\section{Introduction}

Converting renewable biomass into electricity by the use of microbial fuel cells (MFCs) can produce clean and transportable energy. The performance of MFCs has been extensively evaluated on laboratory scales [1]. Thus far, electron suppliers for MFCs have been primarily limited to those soluble and rapidly metabolized organic compounds such as simple carbohydrates [2], [3], small organic acids [3], [4], starch [5], and amino acids [6]. Plant fiber carbohydrates, including waste from agricultural and industrial activity, are the most abundant and renewable biomass on Earth [7]. MFCs offer an opportunity to treat fibrous waste, such as straw, to concurrently generate electricity without the competition of food by humans and animals. In contrast to the non-fiber substrates mentioned above, plant fiber is relatively insoluble and is a large polymer with a diverse and complex structure [8]. Consequently, the biodegradation of fiber, coupled with the electrical output from MFCs, requires the collaborative actions of various microorganisms. In the rumen of ruminants there resides numerous symbiotic microorganisms, consisting of bacteria, protozoa, and fungi. By processing various enzymes, the microorganisms efficiently degrade plant fiber under anaerobic conditions [9], [10] with volatile fatty acids, such as acetate, propionate and butyrate, being produced in the process. During microbial fermentation of organic matter in the rumen a reducing equivalent is produced, which is accompanied by the release and translocation of protons and electrons [11]. These products could theoretically be transformed into

\footnotetext{
* Manuscript received December 28, 2015; revised April 7, 2016.

Corresponding author. Tel.: +88639357400x7459; E-mail address: ctwang@ niu.edu.tw

doi: $10.12720 /$ sgce.5.2.100-105
} 
electricity in MFCs. Little MFC work has been conducted with rumen microorganisms as the biocatalyst and plant fiber as the substrate. Recent research work has demonstrated that purified cellulose could be converted into electricity by rumen microorganisms in MFCs in the absence of exogenous electron transfer mediators [12]. These results indicate that rumen microorganisms could simultaneously degrade cellulose and produce electricity under MFC conditions. In nature, cellulose is always inevitably associated with other components present in the fiber. To date, the direct use of native plant fiber for power generation in MFCs has not been adequately evaluated. The objective of this study was to investigate fermentation characteristics and electrical properties in microbial fuel cells with rumen microorganisms and plant fiber substrate.

\section{Materials and Methods}

Ruminal contents were collected in a previous study [13]. Immediately prior to its morning feed, rumen contents were collected from a cow and rumen fluid extracted by using four layers of cheesecloth and then poured into a thermos flask. Small feed particles were then filtered out of the rumen fluid through eight layers cheesecloth and put into the Serum bottle. In order to maintain the growth of anaerobic microorganisms, a stream of $\mathrm{CO}_{2}$ was put into the Serum bottle containing filtered rumen fluid. In this study, the substrates of Bermuda grass straw, which consisted of $24.4 \%$ cellulose, $37.5 \%$ hemicellulose, $6.47 \%$ lignin and $16.5 \%$ non-fiber carbohydrate was used as rumen fluid. To assure there was enough ammonia for microbial degradation on substrates, an artificial saliva solution, which is found in study [14], was included in the incubations.

\section{Microbial Fuel Cell Experiment}

Replicate MFCs were built in the previous study [13] in which the anode electrode was immersed in anolytes and the cathode electrode was immersed in catholytes. The electrodes were connected by an external resistor of $100 \Omega$ to MFC. Before inoculation, the $\mathrm{CO}_{2}$ saturated artificial saliva $(450 \mathrm{~cm} 3)$ containing $3 \mathrm{~g}$ of Bermuda grass straw, ground down to $1 \mathrm{~mm}$ in size, was first put into the anode chamber. The anode chamber was then gassed with $\mathrm{CO}_{2}$ to the space above the solution after which it was filled with strained rumen fluid $(450 \mathrm{~cm} 3)$ in a stream of $\mathrm{CO}_{2}$. The anode chamber was sealed using rubber stoppers and silicone. A $900 \mathrm{~cm} 3$ solution of $500 \mathrm{~mol} \mathrm{~m}-3 \mathrm{~K}_{3} \mathrm{Fe}(\mathrm{CN})_{6}$ was then entered into the cathode chamber. All the fuel cells were controlled at a temperature of $39^{\circ} \mathrm{C}$ through a water bath. Samples (1.5 $\mathrm{cm} 3$ ) of anode solution were taken every $12 \mathrm{~h}$ after the start of the MFC operation for analysis of VFA by high-performance liquid chromatography (HPLC) [13]. The MFC data was recorded by a data acquisition unit (Data Acquisition System 5020, Jiehan, Taiwan) which was connected to a personal computer. The I$\mathrm{V}$ curve and power density were measured by an electrochemical analyser (Electrochemical Workstation 5600, Jiehan, Taiwan). The total experiment was performed in two runs.

\section{Results}

\subsection{Electricity production in a MFC from straw}

In order to determine the effect that straw added to a MFC had on power, an electrochemical analyser was used to confirm both the MFC performance and obtain an I-V curve and power density chart. Fig. 1 presents the I-V curve and power density of with straw and without straw in the MFC. Straw added in the MFC produces a higher open circuit voltage of $0.64 \mathrm{~V}$, a maximum power density of $435 \mathrm{~mW} / \mathrm{m}^{2}$ and limiting current of $47.7 \mathrm{~mA}$. Without straw added in a MFC produces a higher open circuit voltage of $0.18 \mathrm{~V}$, maximum power density of $47 \mathrm{~mW} / \mathrm{m}^{2}$ and maximum current of $19.3 \mathrm{~mA}$. The power density and limiting current of with straw are 9.25 and 2.47 times than without straw. Fig 2 shows the discharge from the experiment. The MFC was connected an external resistance of $100 \Omega$ after 12 hours. The average voltage of with straw was $0.176 \mathrm{~V}$, and it was similar to without straw. 


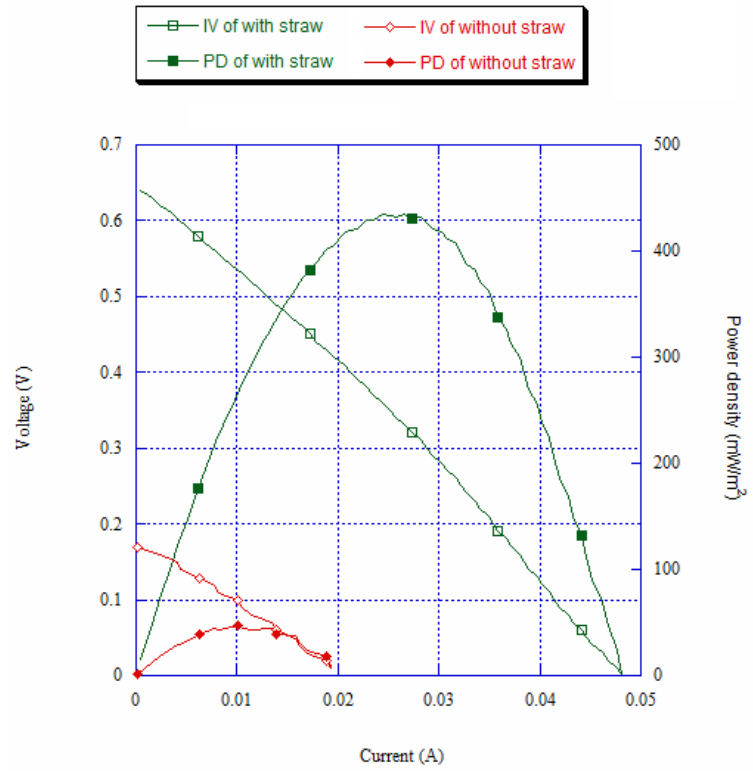

Fig. 1. I-V curve (IV) and power density (PD) of with straw and without straw.

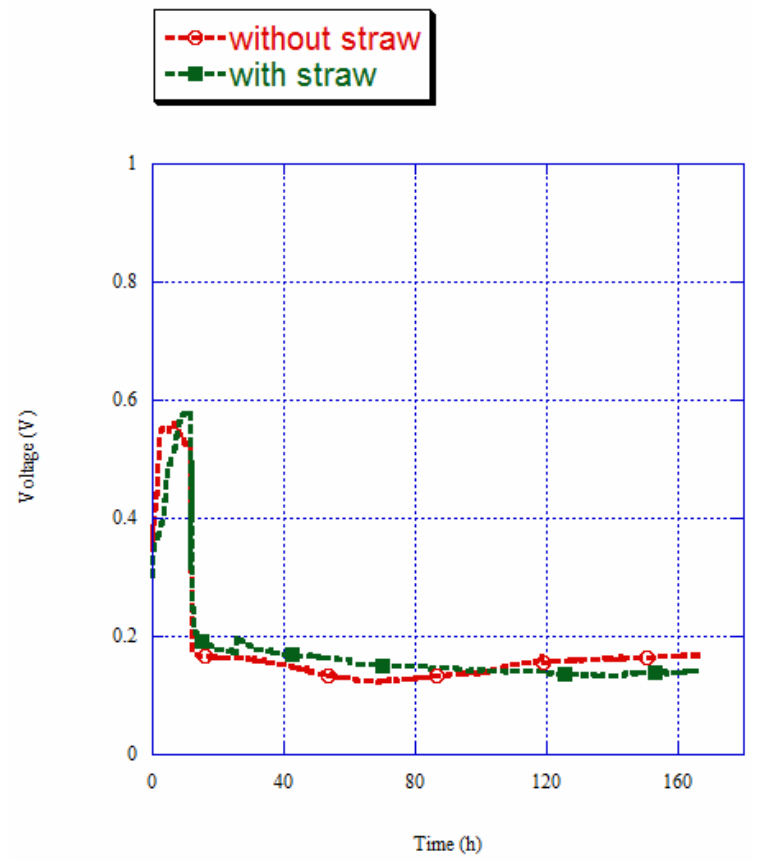

Fig. 2. Discharge experiment in MFC.

\subsection{Incubation of various amounts of straw with ruminal microorganisms}

Fig. 3 shows the changes in VFA during fermentation of straw by ruminal microorganisms in MFCs. Ruminal microorganisms metabolized straw to produce the amount of total VFA (TVFA) which consisted of acetate (C2), propionate (C3) and butyrate (C4) showed in Fig. 3(a). It indicates that the case of with straw had a higher concentration of acetate and propionate, and butyrate was lower for incubation in the case of without straw (Fig. 3b, 3c, 3d). 


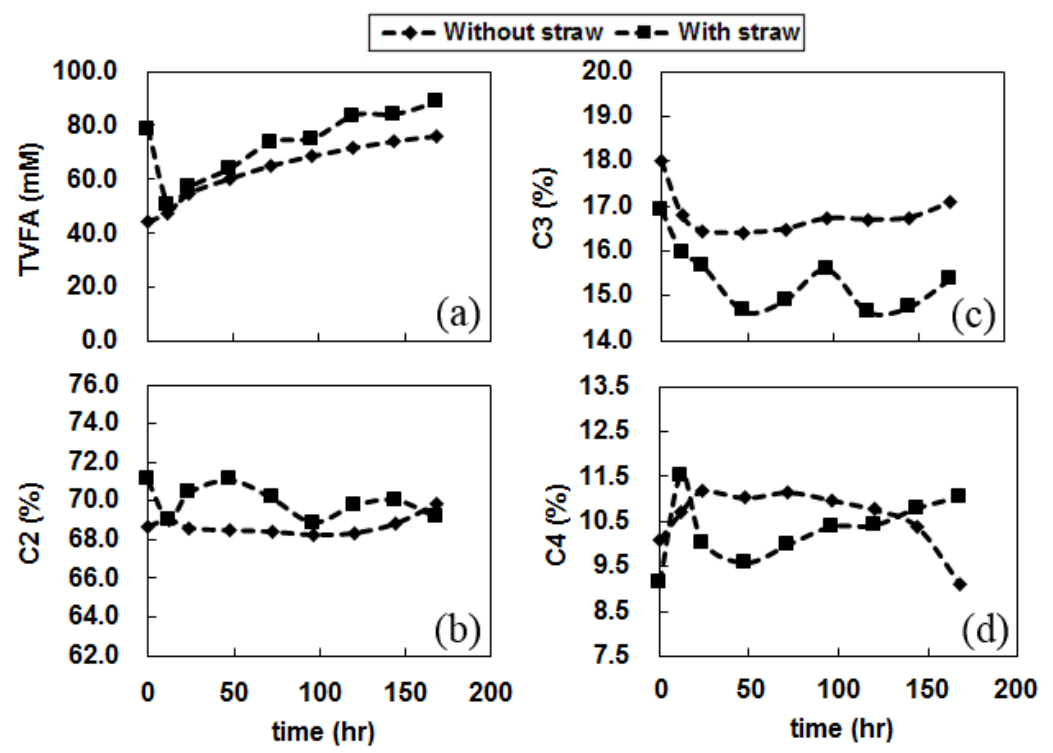

Fig. 3. The amount of change in VFA during fermentation: (a) TVFA (b) C2 (c) C3 and (d) C4.

\section{Discussion}

The electrochemical analysis indicated by straw added in MFCs as a substrate shows that ruminal microorganisms release electrons by metabolizing straw and delay the phenomenon of concentration loss [15]. Electricity production from MFCs supplied with plant fiber has been demonstrated [16], [17]. Through the discharging experiment, it was be found that the average voltage was similar between with straw and without straw. It might be that the external resistance used is too large to limit the transmission of electrons [15]. Jadhav [18] observed that increasing an external resistance in MFCs caused current decreasing. In the Pinto report [19], when external resistance was higher than internal resistance, the current density was limited. On the other hand, when the external resistance was lower than the internal resistance, it resulted in a low power output. Therefore, the external resistance should be close to the internal resistance.

In this study, it was observed that straw added in a MFC system resulted in greater VFA production. Morvay [20] reported the VFAs were produced by rumen microorganism fermentation. Wang [21] indicated that acetate proportions increased with increasing proportions of straw in the substrate. Transmission of electrons usually accompanied the production of VFA [11], [22], [23]. It consumed electrons when propionate was produced and synthesized butyrate by capturing protons [21]. On the other hand, acetate was formed through releasing protons [21]-[24] and electrons [21]. Liu [4] reported that using acetate as the substrate produced more power density than propionate in a single-chambered MFC. Pinto [19] indicated that increasing the concentration of acetate could decrease the internal resistance of MFCs. However, accumulating more VFA might inhibit the activity of the microorganisms. Rezaei [25] observed the cellulose breakdown product acetate was reported to accumulate in MFC but could not fully utilize for power generation. Cheng [26] pointed out that the proton generation by microbial metabolizing acetate, resulting in a $\mathrm{pH}$ drop of the anolytes. This low $\mathrm{pH}$ limited the activity of the microorganisms. Therefore, an acetate-type metabolism would favor the generation of voltage and power by MFCs so long the concentration does not accumulate [21].

\section{Conclusion}

Ruminal fluid which consisted of mixed microorganisms was inoculated into MFCs with straw or without. The typical ruminal microbial fermentation patterns of the VFA, which consisted of acetate, 
propionate and butyrate, were observed. Electricity output was detected, indicating that ruminal microorganisms could degrade straw and produce electricity simultaneously in MFCs. The power density and limiting current of a with straw MFC system are 9.25 and 2.47 times than that without straw in the MFC system. The results of the VFA illustrate that ruminal microbial fermentation could synthesize acetate to release electrons. In other words, an acetate-type of metabolism would favor the generation of voltage and power by MFCs so long as the concentration does not accumulate. These observations would be useful to the power improvement of RMFCs in the future.

\section{Acknowledgements}

Text below continues as normal. The authors acknowledge financial support by National Science Council (NSC- 99-2221-E-197-017, NSC-99-2622-E-197-005-CC3), Taiwan.

\section{References}

[1] Rabaey K, Verstraete W. Microbial fuel cell: novel biotechnology for energy generation. Trends in Biotechnology, 2005; 23(6):291-298.

[2] Rabaey K, Lissens G, Siciliano SD, Verstraete W. A microbial fuel cell capable of converting glucose to electricity at high rate and efficiency. Biotechnology Letters, 2003; 25(18):1531-1535.

[3] Chae KJ, Choi MJ, Lee JW, Kim KY, Kim IS. Effect of different substrates on the performance, bacterial diversity, and bacterial viability in microbial fuel cells. Bioresource Technology, 2009; 100(14):3518-3525.

[4] Liu H, Cheng S, Logan BE. Production of electricity from acetate or butyrate using a single-chamber microbial fuel cell. Environmental Science and Technology, 2005; 39(2):658-662.

[5] Niessen J, Schröder U, Scholz F. Exploiting complex carbohydrates for microbial electricity generation-a bacterial fuel cell operating on starch. Electrochemical Communication, 2004; 6(9):955-958.

[6] Logan BE, Murano C, Scott K, Gray ND, Head IM. Electricity generation from cysteine in a microbial fuel cell. Water Ressource, 2005; 39(5):942-952.

[7] Niessen J, Schröder U, Harnisch F, Scholz F. Gaining electricity from in situ oxidation of hydrogen produced by fermentative cellulose degradation. Letters in Applied Microbiology, 2005; 41(3):286-290.

[8] Malherbe S, Cloete TE. Lignocellulose biodegradation: Fundamentals and applications. Environmental Science and Bio/Technology, 2002; 1(2):105-114.

[9] Hobson PN, Stewart CS. The rumen Microbial Ecosystem. New York: Blackie Academic \& Professional; 1997.

[10] Krause DO, Denman SE, Mackie RI, Morrison M. Opportunities to improve fiber degradation in the rumen: microbiology, ecology, and genomics. FEMS Microbiological Review, 2003; 27(5):663-693.

[11] Offner A, Sauvant D. Thermodynamic modeling of ruminal fermentations. Animal Research, 2006; 55(5):343-365.

[12] Rismani-Yazdy H, et al., Electricity generation from cellulose by rumen microorganisms in microbial fuel cells. Biotechnology and Bioengineering, 2007; 97(6):1398-1407.

[13] Wang CT, Yang CMJ, Chen ZS, Lee YC. Performance of straw-fed microbial fuel cells with mixed rumen microorganisms by using different catholytes. Biomass and Bioenergy, 2013; 59:412-417.

[14] McDougall EI. Studies on ruminant saliva. 1. The composition and output of sheep's saliva. Biochemical Journal, 1948; 43(1):99-109.

[15] Logan BE. Microbial Fuel Cells. 1st ed. New Jersey: Wiley-Interscience; 2008.

[16] Yue ZB, Li WW, Yu HQ. Application of rumen microorganisms for anaerobic bioconversion of lignocellulosic biomass. Bioresource Technology, 2013; 128:738-744.

[17] Song TS, Wang DB, Han S, Wu XY, Zhou CC. Influence of biomass addition on electricity harvesting from solid phase microbial fuel cells. International journal of hydrogen energy, 2014; 39(2):1056-1062.

[18] Jadhav GS, Ghangrekar MM. Performance of microbial fuel cell subjected to variation in $\mathrm{pH}$, temperature, external load and substrate concentration. Bioresource Technology, 2009; 100(2):717-723.

[19] Pinto RP, Srinivasan B, Guiot SR, Tartakovsky B. The effect of real-time external resistance optimization on microbial fuel cell performance. Water Research, 2011; 45(4):1571-1578.

[20] Morvay Y, Bannink A, France J, Kebreab E, Dijkstra J. Evaluation of models to predict the stoichiometry of volatile fatty acid profiles in rumen fluid of lactating Holstein cows. Journal of Dairy Science, 2011; 94(6):3063-3080.

[21] Wang CT, Yang CMJ, Chen ZS. Rumen microbial volatile fatty acids in relation to oxidation reduction potential and electricity generation from straw in microbial fuel cells. Biomass and Bioenergy, 2012; 37:318-329. 
[22] Dijkstra J, Forbes JM, France J. Quantitative Aspects of Ruminant Digestion and Metabolism. CABI Publishing; 1993.

[23] Jeong CM, Choi JDR, Ahn Y, Chang HN. Removal of volatile fatty acids (VFA) by microbial fuel cell with aluminum electrode and microbial community identification with 16S rRNA sequence. Korean Journal Chemical Engineering, 2008; 25(3):535-541.

[24] Rahman MM, Salleh MAM, Sultana N, Kim MJ, Ra CS. Estimation of total volatile fatty acid (VFA) from total organic carbons (TOCs) assessment through in vitro fermentation of livestock feeds. African Journal of Microbiology Research, 2013; 7(15):1378-1384.

[25] Rezaei F, et al., Simultaneous Cellulose degradation and electricity production by enterobacter cloacae in a microbial fuel cell. Applied and Environmental Microbiology, 2009; 75(11):3673-3678.

[26] Cheng KY, Ho G, Cord-Ruwisch R. Affinity of microbial fuel cell biofilm for the anodic potential. Environmental Science and Technology, 2008; 42(10):3828-3834. 